\title{
Oxygenated Leaching of Copper Sulfide Mineral under Microwave- Hydrothermal Conditions
}

\author{
Jiann-Yang Hwang, Shangzhao Shi, Zhiyong Xu and Xiaodi Huang \\ Institute of Materials Processing, Michigan Technological University \\ Houghton, MI 49931
}

\begin{abstract}
A study on microwave assisted chalcocite leaching was carried out with a microwave hydrothermal reactor. The leaching was conducted with thick mineral slurries $(50-100 \mathrm{~g} / \mathrm{l})$. The leaching media is a mixed solution of $\mathrm{CuCl}_{2}$ and $\mathrm{NaCl}$. The investigation included the effect of leaching temperature, quantities of the minerals per unit slurry volume as well as the initial concentration of cupric ions. The results were discussed and compared with using conventional leaching method.
\end{abstract}




\section{Introduction}

As the demands for environment protection are getting more and more urgent, extracting of metals from their sulfide minerals by means of hydrometallurgical approaches becomes more and more attractive. The well-demonstrated advantage of the hydroprocess over the conventional pyroprocess is its avoidance of producing $\mathrm{SO}_{2}$, one of the top industrial pollutants. Another potential advantage of the hydrometallurgical process is the direct electrolysis of copper sulfide [1]. The direct electrolysis of copper sulfide minerals is viewed as the most cost effective and environmentally clean process which industry has developed for over one hundred years [2].

Industrial transformation from the conventional pyrometallugical process to the hydrometallurgical process depends on the overall advantages of a number of technical and economic factors. One such factor is productivity. Only the process with high production rate can be practicable.

Microwave energy has an amazing capability of accelerating chemical reactions. Successful demonstrations include organic and inorganic synthesis [3,4], mineral digestion [5] and extraction [6]. While the microwave assistance in hydrothermal synthesis of ceramic powders has achieved the kinetic acceleration in one to two order of magnitudes [7], microwave assisted chloride leaching of copper minerals at reflux temperature has achieved about three times enhancement [8].

In this work the study of microwave-assisted leaching under hydrothermal conditions was conducted. Oxygen was used as the exogenous pressure supply, since it had been employed as the primary oxidizing agent for decomposition of the copper sulfide minerals $[9,10]$.

\section{Experimental}

The copper sulfide mineral was a chalcocite from Butte, Montana, supplied by Ward's Natural Science Establishment, Inc. Its chemical composition was analyzed by ALS Chemex Labs, Inc., which showed that it contains $47.7 \% \mathrm{Cu}, 21.4 \% \mathrm{~S}$ and $11.5 \% \mathrm{Fe}$. X-ray diffraction patterns (Fig.3) showed the mineral is actually composed of spionkoptite $\left(\mathrm{Cu}_{39} \mathrm{~S}_{28}\right)$, geerite $\left(\mathrm{Cu}_{8} \mathrm{~S}_{5}\right)$, an unnamed phase $\left(\mathrm{Cu}_{5} \mathrm{FeS}_{4}\right)$ and some pyrite $\left(\mathrm{FeS}_{2}\right)$ and quartz as impurities. The mineral was crushed and ball-milled to -200 mesh before leaching procedure. Possible iron contamination from the milling was removed by means of a magnet. Aqueous solution of $\mathrm{CuCl}_{2}$ $\mathrm{NaCl}-\mathrm{HCl}$ was used as the leaching agent.

Leaching of the mineral was carried out in a self-installed microwave-hydrothermal reactor, as shown in Fig.1. For each batch, $4000 \mathrm{ml}$ of leaching solution is charged into the reactor. While the concentration of $\mathrm{NaCl}$ was kept constant $(0.4 \mathrm{M})$, the concentration of $\mathrm{CuCl}_{2}$ varied for different leaching trials. The concentration of $\mathrm{HCl}$ was also varied accordingly in order to keep the total concentration of $\mathrm{Cl}^{-}$constant (1.9M).

Leaching slurries were exposed to $2.45 \mathrm{GHz}$ microwave radiation. With a power of $4 \mathrm{~kW}$ irradiation, the slurries were heated to their leaching temperatures. The power was then turned down to an appropriate value to keep the leaching temperature constant. Oxygen was supplied before the irradiation of microwaves and the pressure was kept constant throughout the procedure. The slurries were stirred constantly at $300 \mathrm{rpm}$ during leaching, which was detected by a tachometer (Omega, HHT11). 
The leached solids were separated from their solutions and washed first with $1 \mathrm{~N} \mathrm{HCl}$, then with deionized water several times. After being dried in vacuum at $75^{\circ} \mathrm{C}$, they were dissolved into concentrated $\mathrm{HCl}$ for ICP analysis of copper in the solids. XRF and XRD characterization of the solids were also performed in order to assist in the assessment of the leaching process.

\section{Result and discussion}

\section{$\underline{\text { Fast leaching kinetics }}$}

The study shows that the microwave hydrothermal leaching is a fast process. Under leaching conditions of temperature, $135^{\circ} \mathrm{C}$; oxygen pressure, $45 \mathrm{psi}$; weighed-in $\mathrm{CuCl}_{2}$ concentration, $0.25 \mathrm{M} ; \mathrm{NaCl}$ concentration, $0.4 \mathrm{M} ; \mathrm{HCl}, 1.0 \mathrm{M}$, leaching of $400 \mathrm{~g}$ of mineral was completed in 3 hours and leaching of $200 \mathrm{~g}$ of mineral was completed in 1 hour. XRF results showed no signs of copper in these solids. Complete decomposition of the mineral was also indicated by ICP analysis (Fig.2). XRD shows that the sulfur exists in the solids as elemental sulfur and no other forms of copper sulfide compounds appeared (Fig.3).

It has been reported that conventional leaching has the capability to achieve over $90 \%$ copper extraction within 30 minutes [10]. However, the weighed-in mineral in Ruiz, etc. was considerably less than that in this experiment, $10 \mathrm{~g} / 1 \mathrm{vs} 50-100 \mathrm{~g} / \mathrm{l}$. While the initial ratio of the oxidant copper to the mineral copper in Ruiz's case was about 1.21, the corresponding ratio in this experiment was 0.33 . The oxidation by $\mathrm{Cu}^{2+}$ is a fast process, high starting $\left[\mathrm{Cu}^{2+}\right]$-to-mineral ratio is able to dramatically increase the initial leaching rate [11]. Also, the ratio of the total chloride ions to the mineral copper in their case was about 5.09, but the corresponding ratio in this study was about 2.53. Higher chloride ion concentration also contributes to higher leaching rate [12]. This study, however, selected to use low $\left[\mathrm{Cu}^{2+}\right]$ and $\left[\mathrm{Cl}^{-}\right]$starting concentrations, in order that more minerals can be charged and leached before $\left[\mathrm{Cu}^{2+}\right]$ and $\left[\mathrm{Cl}^{-}\right]$reach saturation.

\section{Effect of temperature}

Fig.4 shows the leaching rate increase with temperature, although conventional leaching observed a maximum at around $90^{\circ} \mathrm{C}$. This different leaching profile in this study may be due to the microwave-hydrothermal effect. At $90^{\circ} \mathrm{C}$ and below, much less microwave energy was required to keep the temperature constant. The leaching results were similar to the conventional approach. However, microwave energy required for keeping the leaching temperature increases as the experimental temperature increases and reached to about $0.8 \mathrm{~kW}$ at $135^{\circ} \mathrm{C}$.

Among a number of mechanisms dealing with the microwave enhancement effect, one common recognition is that the high frequency electromagnetic waves have the capability to concentrate their energy on charged ions (selectively super heating [13] these ions). For aqueous system, although water is a good microwave absorber, its dielectric loss factor drops from above 20 to below 5 as the temperature rises from $3{ }^{\circ} \mathrm{C}$ to $95^{\circ} \mathrm{C}[14,15]$. We may assume a further decrease of the dielectric loss factor of water at temperatures above its boiling point. High temperatures tend to cause water molecules to become more symmetric, while the increasing symmetry means the decrease of polarity and therefore the decrease of dielectric loss factor. The decrease of the loss factor of water may facilitate the concentrating of microwave energy on the reaction species and thus accelerate the leaching process. 


\section{Effect of $\mathrm{CuCl}_{2}$ concentration}

Fig.5 shows the effect of the weighed-in cupric chloride concentration on the mineral decomposition. While the after-0.5h-leaching decomposition was affected by the concentration of cupric chloride appreciably, the after-1.5h leaching decomposition remained almost unaffected. This phenomenon implies that the leaching process was controlled by different mechanisms in these two stages.

The oxygenated chloride leaching of copper sulfide minerals can be represented by the following reactions [10]:

$$
\begin{aligned}
& \mathrm{Cu}_{2} \mathrm{~S}+2 \mathrm{Cu}^{2+}=4 \mathrm{Cu}^{+}+\mathrm{S}^{0} \\
& \mathrm{Cu}^{+}+\mathrm{H}^{+}+0.25 \mathrm{O}_{2}=\mathrm{Cu}^{2+}+0.5 \mathrm{H}_{2} \mathrm{O} \\
& \mathrm{Cu}_{2} \mathrm{~S}+2 \mathrm{H}^{+}+0.5 \mathrm{O}_{2}=2 \mathrm{Cu}^{+}+\mathrm{H}_{2} \mathrm{O}+\mathrm{S}^{0}
\end{aligned}
$$

Previous researchers have observed fast kinetics both for decomposition of copper sulfide minerals by $\mathrm{Cu}^{2+}[11]$ and for oxidation of $\mathrm{Cu}^{+}$to $\mathrm{Cu}^{2+}$ by oxygen [16,17]. We therefore assume that reaction (1) and (2) were responsible for the leaching in this case. Based on the complexation preference of $\mathrm{Cu}^{+}-\mathrm{Cl}^{-}$to $\mathrm{Cu}^{2+}-\mathrm{Cl}^{-}$[18], we further assume that reaction (1) was even faster than reaction (2) in the presence of substantial chloride ions in the solution.

At the initial stage, the oxidation ions, $\mathrm{Cu}^{2+}$, were directly weighed in and the different weighed-in concentrations affected the rate of reactions, i.e. decomposition of the mineral. As the leaching proceeded, the weighed-in $\mathrm{Cu}^{2+}$ ions were consumed and further proceeding of reaction (1) relied on the new $\mathrm{Cu}^{2+}$ ions generated by reaction (2). The lower rate of the reaction overshadowed the effect of weighed-in $\mathrm{Cu}^{2+}$ concentration on leaching in the late stage.

The existence of microwave effect can not be identified from this aspect and more informative experiments should be designed and carried out, which include the change of microwave radiation intensity.

\section{Conclusion}

Fast kinetics of oxygenated chloride leaching of chalcocite has been observed under microwave hydrothermal conditions. Thick mineral slurries $(100 \mathrm{~g} / \mathrm{l})$ can be completely decomposed within 3 hours with relatively low weighed-in $\mathrm{Cu}^{2+}$ and $\mathrm{Cl}^{-}$concentrations.

The fast leaching kinetics was attributed to the microwave-induced super heating of copper ions, which becomes more significant as the leaching temperature rises.

The weighed-in $\mathrm{Cu}^{2+}$ concentration affected the leaching kinetics at the early stage but had little effect in the later. This is explained in comparison of the rates of the reactions involved in the leaching. Whether microwave had an effect on this aspect is not clear and needs further study. 


\section{Reference}

1. M. Valayapetre and A.E. Torma; "Electrochemical recovery of copper from covellite"; Metal, 32 [11] 1120-1123 (1978).

2. D.J.Mckay; " The direct electrorefining of copper matte", JOM, 44-48 (1993)

3. A.K. Bose, B.K. Banik, N. Lavlinskaia, M. Jayaraman and M.S. Manhas; "MORE chemistry in a microwave"; Chmtech, 18-23, 1997.

4. S.S. Park; "Synthesis of alumina sulfate from kaolin by microwave extraction"; J. Am. Ceram. Soc., 83 [6] 1341-45 (2000).

5. Anon; "Microwave dissolution"; Analytical Chemistry; 58 (14) 1424a 1426a (1986)

6. K.E. Haque; "Microwave energy for mineral treatment processes - a brief review"; Int. J. Miner. Process, 57 1-24 (1999).

7. U. Oberhagemann, M. Jeschke and H. Papp; "Synthesis of highly ordered boron-containing BMCM-41 and pure silica MCM-41"; Microporous and Mesoporous Materials; 33 165-172 (1999)

8. W. Ding; "Leaching behavior of complex copper sulfide concentration with ferric chloride by microwave irradiation"; Rare Metals, 16 [2] 152-155 (1997).

9. R. Padilla, D. Lovera and M.C. Ruiz; "Leaching of chalcopyrite in $\mathrm{CuCl}_{2}-\mathrm{NaCl}-\mathrm{O}_{2}$ system"; EPD Congress 1997, 167-177 (1997).

10. M.C. Ruiz, S. Honores and P. Padilla; "Leaching of a chalcocite concentrate with cupric chloride-oxygen"; EPD Congress 1997, 139-147 (1997).

11. M.C. Ruiz, S. Honores and R. Padilla; "Leaching of Digenite concentrate in oxygenated chloride media at ambient pressure"; Metallurgical and Materials Transactions B, 29B 961969 (1998).

12. R.Z. Vracar, I.S. Parezanovic and K.P. Cerovic; "Leaching of Copper(I) sulfide in calcium chloride solution"; Hydrometallurgy, 58 261-267 (2000).

13. F. Chemat, D. C. Esveld, M. Poux and J. L. Dimartino; "Role of selective heating in the microwave activation of heterogeneous catalysis reactions using a continuous microwave reactor": J. Microwave Power and Electromagnetic Energy; 33 (2) 88-94 (1998).

14. I.S. Hudiara, "Microwave complex permitivity of water at high temperatures", IETE Technical Review, 15 [3] 221-223 (1998).

15. S. Ryynanen, P.O. Risman and T. Ohlsson, "The dielectric properties of native starch solutions - a research note", Journal of Microwave power and Electromagnetic Energy, 31 [1] 50-53 (1996).

16. A.S. Jhaveri and M.M. Sharma; "Kinetics of absorption of oxygen in aqueous solutions of cuprous chloride"; Chem. Eng. Sci., 22 1-6 (1967).

17. T. Tran and D.A.J. Swinkels; "The kinetics of oxidation of $\mathrm{Cu}$ (I) chloride by oxygen in NaCl-HCl solutions"; Hydrometallurgy, 15 281-295 (1986).

18. R. Winand; "Chloride hydrometallurgy"; Hydrometallurgy, 27 285-316 (1991). 


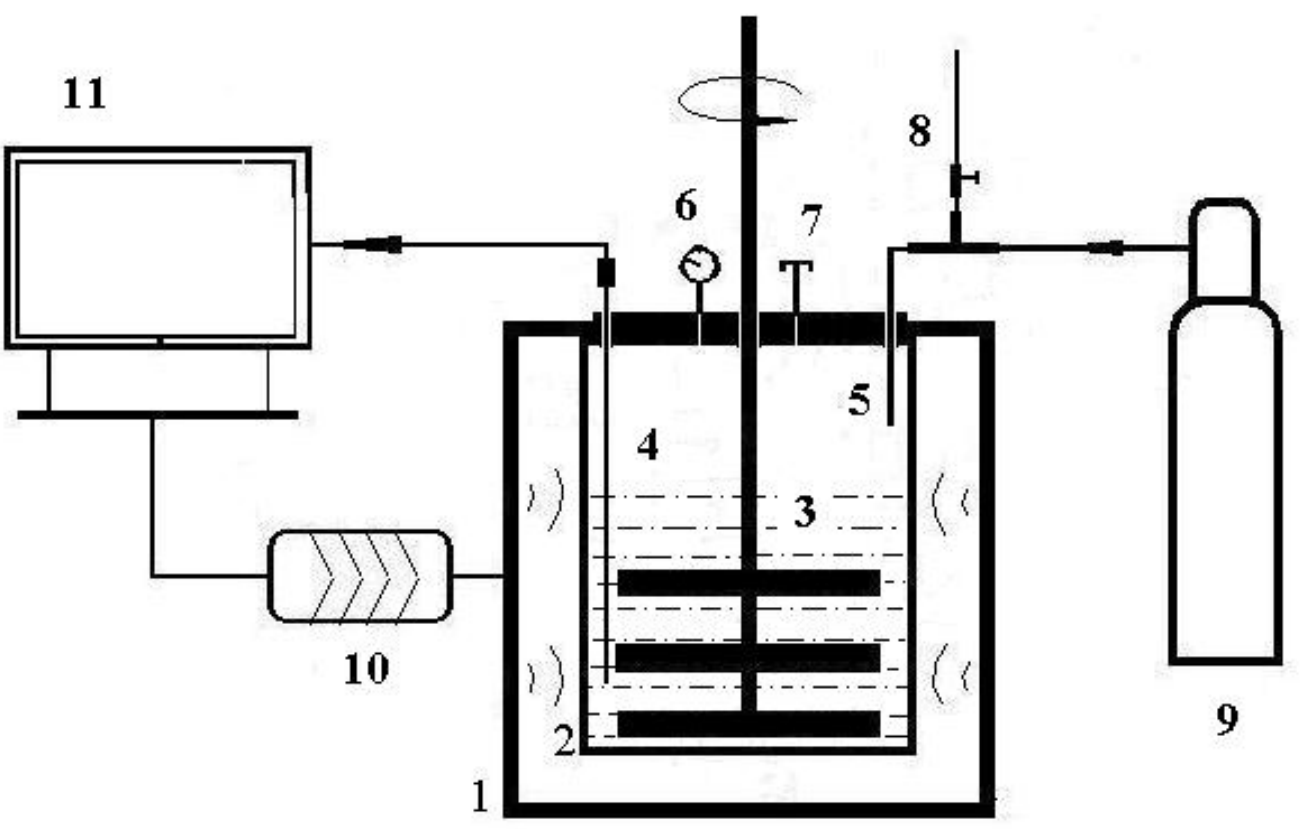

Fig.1 Microwave-hydrothermal reactor used for chloride leaching of copper sulfide minerals under oxygen pressure 1-microw ave applicator, 2-reactor vessel, 3-stirrer, 4-thermocouple, 5-pressure supply pipe, 6-pressure gauge, 7-pressure relief valve, 8-pr essure unload valve, 9-oxygen tank, 10-microw ave generator, 11-microw ave power contr oller 


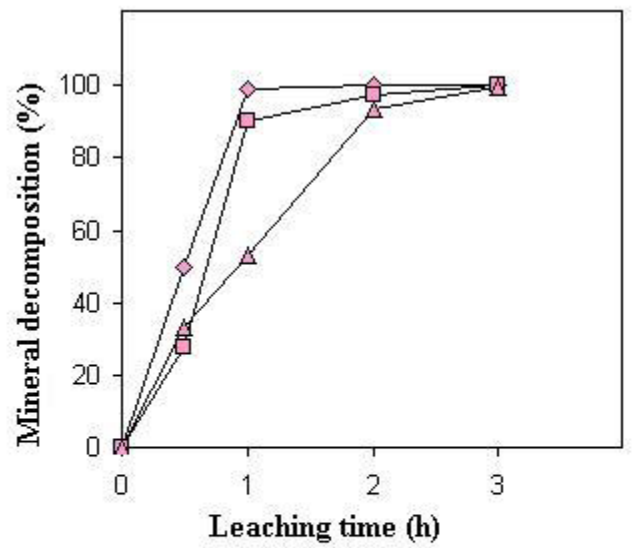

Fig.2 Microw ave-hydrothermal leaching of chalcocite at $135^{\circ} \mathrm{C}$ under $45 \mathrm{p}$ si oxygen pressure

$\multimap-\mathrm{CuCl}_{2}: 0.25 \mathrm{M}$; chalcocite: $50 \mathrm{~g} / \mathrm{l} ; \mathrm{HCl}: 1.0 \mathrm{M}$; $\mathrm{NaCl}: 0.4 \mathrm{M}$

$\rightarrow \square \mathrm{CuCl}_{2}: 0 \mathrm{M}$; chalcocite: $50 \mathrm{~g} / \mathrm{l} ; \mathrm{HCl}: 1.5 \mathrm{M} ; \mathrm{NaCl}: 0.4 \mathrm{M}$

$\rightarrow \mathrm{CuCl}_{2}: 0.25 \mathrm{M}$; chalcocite: $100 \mathrm{~g} / \mathrm{l} ; \mathrm{HCl}: 1.0 \mathrm{M} ; \mathrm{NaCl}: 0.4 \mathrm{M}$ 


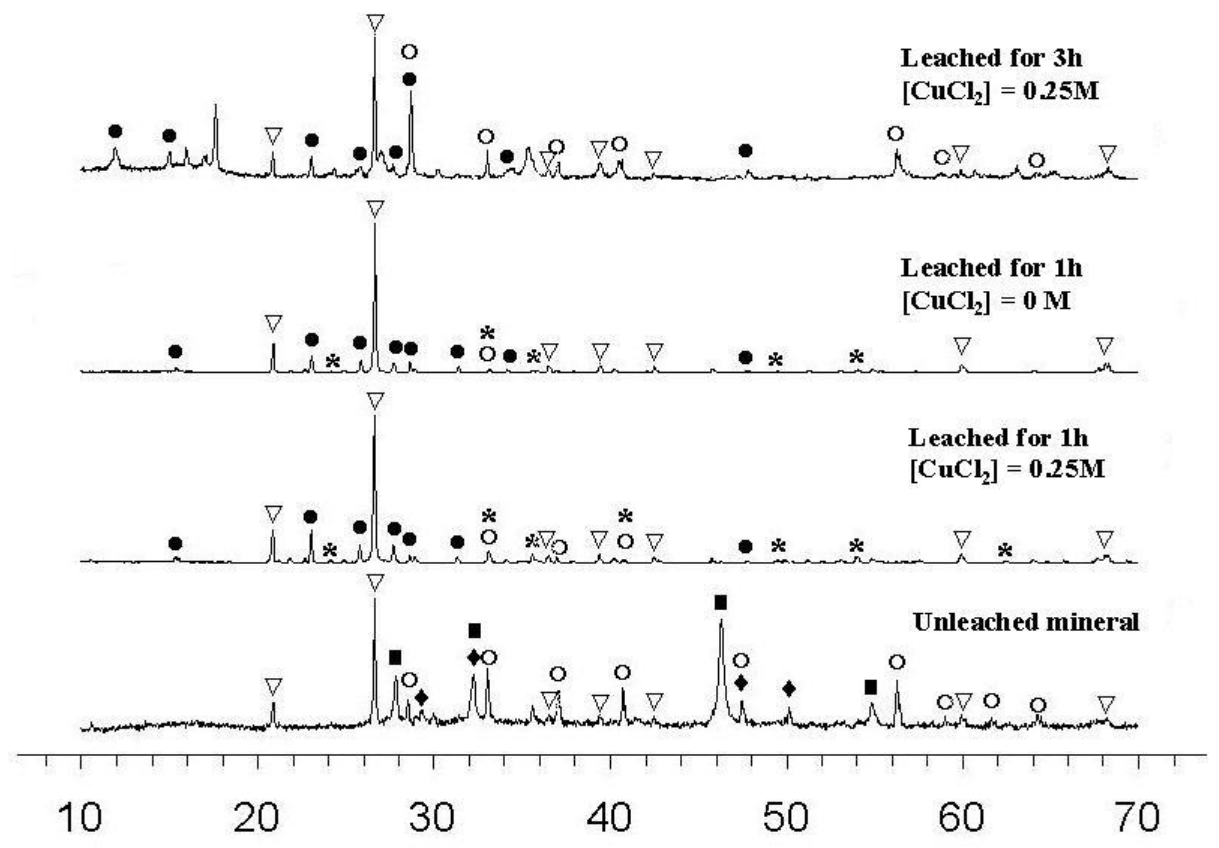

Fig.3 XRD patterns of leached and unleached Chalcocite minerals - Sulfur, \$Spionkoptite, $\square \mathrm{CuFeS}_{5}$, o Pyrite, * Hematite $\nabla$ Quartz. 


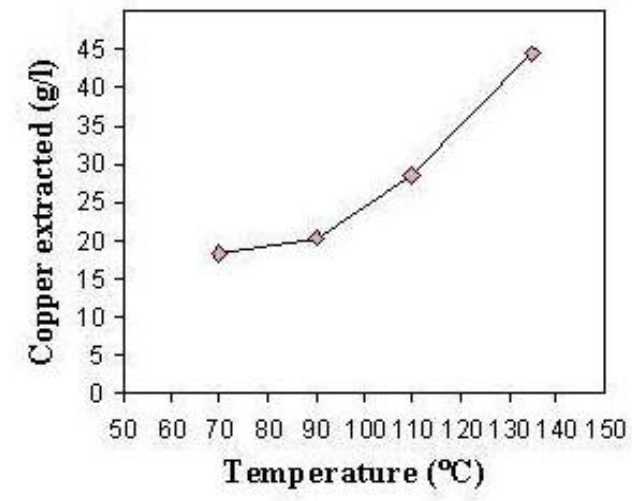

Fig.4 Effect of temperature on leaching Chalcocite: $100 \mathrm{~g} / \mathrm{l} ; \mathrm{CuCl}_{2}: 0.25 \mathrm{M} ; \mathrm{NaCl}: 0.4 \mathrm{M}$; HCl: 1.0M; leaching time: 2 hours

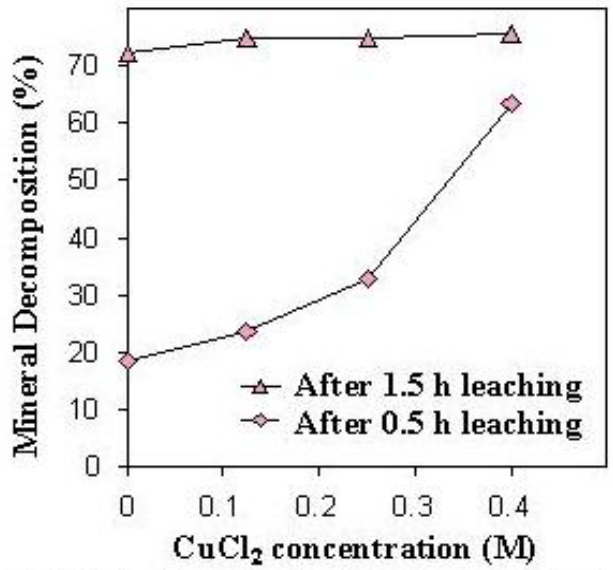

Fig.5 Effect of weighed-in $\mathrm{CuCl}_{2}$ concentratration on the leaching. L eaching conditions: $135^{\circ} \mathrm{C}, 45 \mathrm{p}$ si oxygen pressure, $0.4 \mathrm{M} \mathrm{NaCl}, 100 \mathrm{~g} / 1$ mineral and the $\mathrm{HCl}$ concentration varied with the $\mathrm{CuCl}_{2}$ to keep a c onstant $\left[\mathrm{Cl}^{-}\right]$of $1.9 \mathrm{M}$. 